\title{
UCLA
}

Mester

Title

Toreo Cerebral

Permalink

https://escholarship.org/uc/item/74s8d6nd

Journal

Mester, 3(2)

Author

Pillet, Félix

Publication Date

1973

DOI

10.5070/M332013455

Copyright Information

Copyright 1973 by the author(s). All rights reserved unless otherwise indicated. Contact the author(s) for any necessary permissions. Learn more at https://escholarship.org/terms

Peer reviewed 


\section{Toreo Cerebral}

\section{A Paco Camino}

LUZ

ArTe
orgullo de tardes
clamor
himno unánime
alegria de tierra mojada

todo transcurría rápidamente

en el

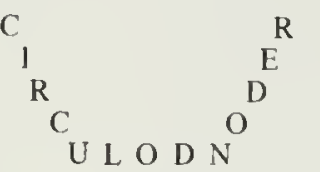
TODA UNA MAESTRIA
d-i-s-e-m-i-n-a-d-a
en el filo del acero

kilos de trapio

bien- I e parti d ${ }^{\mathrm{s}}$

toda una masa negra

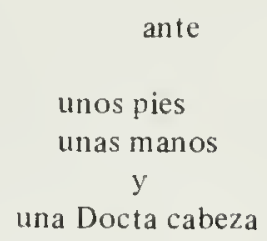

de cabellos bien sentados

-Félix Pillet 